\title{
A cross-sectional study on self-reported physical and mental health-related quality of life in rheumatoid arthritis and the role of illness perception
}

\author{
Carolin Berner ${ }^{1,2^{*}}$ (D) Ludwig Erlacher ${ }^{1,2}$, Karl Heinrich Fenzl ${ }^{2}$ and Thomas E. Dorner ${ }^{3}$
}

\begin{abstract}
Background: Psychosocial models including illness perception might explain individual differences in health-related quality of life (HRQoL) and daily functioning in chronically ill patients. The aim of this study was to assess the association of illness perception among rheumatoid arthritis (RA) patients with physical and mental HRQoL, adjusted for demographic variables, clinical variables and social support.

Methods: A cross-sectional study conducted at a Viennese rheumatology outpatient clinic on 120 RA patients. Participants completed questionnaires on demographic and clinical characteristics, HRQoL (SF-36 Questionnaire), illness beliefs (Brief Illness Perception Questionnaire) and social support (Social Support Scale-8). Analyses were performed with multivariate linear regression.

Results: The mean physical was lower (38.38) than the mean mental SF-36 summary score (46.94). In univariate analysis, all domains of illness perception except belief in a chronic disease course were associated with physical and mental HRQoL. In multivariate analyses, illness perception accounted for $51 \%$ of variance in physical HRQoL. A stronger belief in the consequences of RA (consequences, $\beta=-0.33$ ) and a stronger belief in repeated disease recurrence (timeline cyclical, $\beta=-0.31$ ) were significantly associated with physical HRQoL in the fully adjusted model. Illness perception accounted for $45 \%$ of variance in mental HRQoL. Emotional representation ( $\beta=-0.27$ ) and fatigue ( $\beta=-0.36$ ) were significantly associated with mental HRQoL in the fully adjusted model.
\end{abstract}

Conclusion: This study highlights the importance of RA patients' beliefs about their illness and symptoms in relation to HRQoL. Identification of patients' perception of RA may be a way to positively influence disease outcomes such as quality of life as illness perception is amenable to intervention.

\section{Introduction}

Rheumatoid arthritis (RA) is a chronic systemic disabling condition with a global prevalence of an estimated $0.2-1.0 \%$ [1] that can lead to impairment in activities of daily living and work productivity and compromise the overall well-being of RA patients [2]. In RA, the presentation and course of the disease are individual for every

\footnotetext{
* Correspondence: carolin.berner@gmx.net; carolin.berner@wienkav.at ${ }^{1}$ Sozialmedizinisches Zentrum-Süd, Department of Rheumatology and Osteology, Kaiser Franz Josef Hospital, Vienna Kundratstrasse 3, 1100 Vienna Austria

${ }^{2}$ Karl Landsteiner Institute for Autoimmune Diseases and Rheumatology, Vienna, Austria

Full list of author information is available at the end of the article
}

patient. The severity of the disease can be confined to mild articular affection or manifested as severe, multisystem disease. Also, individuals' perceptions of single symptoms differ and have been attributed to individual differences in adaptation to rheumatoid arthritis [3, 4]. Despite significant improvements in the medical management, treatment and prognosis of RA, it is common for patients to experience deficits in physical and mental health functioning $[5,6]$. The burden of disease in RA depends on both emotional and physical components and the respective impact on overall well-being may vary in individual patients. As specific RA therapy usually targets specific outcomes (e.g. disease activity), the evaluation of its success is mostly seen from the clinical

(c) The Author(s). 2018 Open Access This article is distributed under the terms of the Creative Commons Attribution 4.0 International License (http://creativecommons.org/licenses/by/4.0/), which permits unrestricted use, distribution, and reproduction in any medium, provided you give appropriate credit to the original author(s) and the source, provide a link to the Creative Commons license, and indicate if changes were made. The Creative Commons Public Domain Dedication waiver (http://creativecommons.org/publicdomain/zero/1.0/) applies to the data made available in this article, unless otherwise stated. 
view and rarely includes a patient's overall health-related quality of life (HRQoL) [7, 8]. Therapeutic interests thus increasingly shift from merely symptomatic treatment to restoring, or at least improving, HRQoL [8].

Despite similar levels of disease activity and severity, rheumatologists have observed individual variations in HRQoL. Therefore, more and more emphasis is put on other factors in addition to a strict medical/symptomrelated model. Social support, for example, has a substantial effect on QoL [9] and previous research has shown that social support has beneficial effects on RA patients [10, 11].

Also, psychosocial models were discussed as a framework to explain these individual differences in HRQoL and daily functioning in chronically ill patients $[5,12]$. An individual's reaction and adaptation to a health threat such as a chronic disease depends on the individual's cognitive and emotional representation of this threat in their mind [13]. This psychological factor, which is considered to be an important determinant of perception [14].

In the Common-Sense Model (CSM) of Howard Leventhal and colleagues, illness perception is the key construct that suggests that people have personal beliefs about their illness that often do not match medical views but that nevertheless determine, to a large extent, how people respond to their illness. [15] Illness perception is not only based on symptoms, but also on illness related consequences, past experiences of illness and associated anxiety. [16] Research suggests, that patients cluster their ideas about an illness around five coherent themes or components. These components together make up the patient's perception of their illness. The components provide a framework for patients to make sense of their symptoms, assess health risk, and direct action and coping. Each of these components holds a perception about one aspect of the illness and together they provide the individual's coherent view of an illness. The components include the timeline of the disease, the ability to control the disease and the extent to which the treatment helps in controlling the disease, the understanding of the cause, and the consequences and the emotional response to them. It also includes the perception of symptoms and the labels attributed to the disease (identity) $[15,17,18]$.

Illness perception has a significant implication for adaptation to illness and has been shown to outweigh the impact of medical disease status on depression, physical function and pain and play an important role in the explanation of distress outcome in chronic illness including rheumatic disease [19-21]. It influences how anxious or depressed a patient becomes and these effects may be moderated by other factors such as levels of social support and the presence of additional co-morbidities [22]. In earlier studies, patients' beliefs about their RA have been related to outcomes such as disability, psychiatric morbidity and pain when clinical measures have not
[23]. In chronic disease, cognitive therapies are partly directed at influencing illness beliefs, they are thus amenable to interventions [24].

We assume that, in RA patients, specific beliefs in the timeline of the disease, the ability to control the treatment, the consequences, the comprehensibility of the disease and the emotional response are related to physical and mental HRQoL. Thus, in the present study, we aimed to analyse the association of these illness perceptions with physical and mental HRQoL in patients with RA.

\section{Material and methods}

\section{Study design and sample}

This cross-sectional study was conducted in the rheumatology department at the Kaiser Franz Josef Hospital in Vienna, Austria. RA patients were consecutively screened by their rheumatologist for eligibility during regular outpatient visits. Patients were considered eligible to participate if they had a confirmed diagnosis of RA and a stable disease course with an RA drug regimen for at least 3 months prior to entering the study. Participants had to be $\geq 18$ years old, had to live at home independently and had to be both physically and mentally able to read, understand and complete the questionnaires. Patients were excluded if they had participated in another study and if they had any significant co-morbidity (e.g. advanced cancer or serious mental health problems).

The study was conducted in accordance with the Helsinki Declaration. Ethical review committee approval was obtained from the city government of Vienna (ERB no.: EK-13-190-VK). Participants received detailed information about the study and written informed consent was obtained from each patient before enrolment.

\section{Measures}

Patients were addressed during their regular visits at the outpatient department. A questionnaire package comprising socio-demographic and clinical data, and social support, quality of life and illness perception items was administered to, and completed by, each participant. The sociodemographic variables were sex, age, marital status, educational level and monthly income. Clinical data included disease duration, current RA treatment, the presence of co-morbidities and the number of routine medications (other than RA medication). The subjective perception of current disease activity, pain, fatigue and functional disability was measured on a visual analogue scale, resulting in a score between 0 and 100 .

\section{Health-related quality of life}

The Medical Outcome Study 36-item Short-Form Health Survey (SF-36) $[25,26]$ is an internationally frequently used instrument for operationalizing HRQoL and has been used for various diseases and in many different health-care 
settings. It measures HRQoL as the extent to which physical health influences an individual's functional ability and perceived emotional well-being. In RA, the SF-36 has been found to be a reliable and valid instrument, correlating well with disease-specific measures [27]. For our Austrian outpatient population, we used the validated German version of the SF-36 [28].

The SF-36 has eight dimensions comprising limitations in physical activities due to health, social limitations due to physical and emotional problems, limitations in usual role activities due to physical problems, role limitations due to emotional problems, bodily pain, general mental health, vitality and general health perception. Answer formats range from two- to six-point scales and subscales are summed scores that are converted to percentages. Subscale scores can be combined into two summary scores, one for the physical component (assessing role functioning due to physical problems, general physical function, vitality, pain and general health perception) and one for the mental component (assessing social and role functioning, vitality, mental health and general health perception). The scores are calculated by weighting the four subscales positively in the physical domain and negatively in the psychological domain subscales for the Physical Component Summary (PCS) and the reverse for the Mental Component Summary (MCS). Scores range from 0 to 100 , with higher scores indicating better functioning $[25,26]$.

\section{Illness perception}

Based on Leventhal's Common-Sense Model [15], the Illness Perception Questionnaire (IPQ) was designed to assess underlying dimensions of patients' perception of their illness. The instrument has good psychometric properties and has been used in a variety of illnesses including RA $[29,30]$. For this study, a revised, -RA-specific version of the questionnaire was used (IPQ-R) [29]. The IPQ-R was translated and validated in German [31].

The IPQ-R contains nine scales representing the dimensions underlying the patients' individual perceptions. The scales and implications of the IPQ-R are listed in Table 1.

The identity scale provides a measure of the perceived symptom load with a high score indicating a greater number of symptoms. It is assessed by asking the participants which of 14 symptoms they have experienced during their RA and to identify the symptoms they feel are related to their RA. A high score on the personal control scale and treatment control scale indicates a greater perceived personal control of the disease and a greater perceived control by medical treatment, respectively. The timeline acute/chronic and timeline cyclical scales reflect the assumption about chronicity and recurrence of the illness. A higher score on the consequences scale implies a belief in a stronger influence of the disease upon everyday life and a higher score on the coherence scale indicates a better comprehension (understanding) of the disease. A stronger negative emotional response to the illness is indicated by a higher score on the emotional representation scale. The causes scale refers to the causal beliefs about RA. As this scale simply indicates which causal attributions they endorse, it is statistically not useable and was thus not included in the study.

The identity scale is scored by summing the symptoms each patient experienced during, and attributed to, the

Table 1 Means (and standard deviations) across illness perception (IPQ-R), social support (SSUK) and health- related quality of life (SF-36) scales and description of scores

\begin{tabular}{|c|c|c|c|c|}
\hline & Items in scale/ Ref Range & Mean (SD) & Min-max & Higher score implies \\
\hline \multicolumn{5}{|l|}{ Illness perception } \\
\hline Identity & $14 / 0-14$ & $4.49(2.54)$ & $1-13$ & More symptoms experienced and attributed to RA \\
\hline Timeline (acute/chronic) & $5 / 5-25$ & $20.48(3.53)$ & $6-25$ & Stronger belief in chronic course of RA \\
\hline Consequences & $5 / 5-25$ & $15.00(5.25)$ & $5-24$ & Greater perceived influences of RA \\
\hline Treatment control & $4 / 4-20$ & $13.53(2.66)$ & $5-20$ & Greater perceived control by RA treatment \\
\hline Personal control & $4 / 4-20$ & $12.64(3.32)$ & $4-20$ & Greater perceived personal control \\
\hline Illness coherence & $5 / 5-25$ & $15.88(4.21)$ & $5-25$ & A better understanding of the illness \\
\hline Timeline (cyclical) & $4 / 4-20$ & $13.53(3.30)$ & $6-20$ & Stronger belief in repeated recurrence of RA \\
\hline Emotional representation & $5 / 5-25$ & $14.74(5.16)$ & $5-25$ & Greater feelings of concern about RA \\
\hline \multicolumn{5}{|l|}{ Social support } \\
\hline Positive support & $4 / 0-16$ & $12.7(3.2)$ & $4-16$ & Higher level of positive social support \\
\hline Negative interaction & $4 / 0-16$ & $5.5(3.7)$ & $5-16$ & Higher level of detrimental social interactions \\
\hline \multicolumn{5}{|l|}{ Health-related quality of life } \\
\hline \multirow{2}{*}{$\begin{array}{l}\text { Physical quality of life } \\
\text { Mental quality of life }\end{array}$} & / & $38.38(9.76)$ & $13.84-57.34$ & Better physical quality of life \\
\hline & / & $46.94(12.53)$ & $13.89-68.98$ & Better mental quality of life \\
\hline
\end{tabular}

$R A$ rheumatoid arthritis 
illness. The remaining scales are rated by the patient on a five-point scale ranging from 'strongly disagree' to 'strongly agree'. After reverse scoring, items are then summed to the single category scores.

\section{Social support}

The eight-item Illness-specific Social Support Scale (SSUK-8) was used to assess the subjective perception of social support in chronically ill patients. It is the brief form of the validated German adaptation of the illnessspecific Social Support Scale (SSUK). Items are scored on a five-point Likert scale, converted and summed up into two subscales: positive support and detrimental interactions. Scores range between 1 and 4, with higher scores on each scale indicating higher levels of positive support and higher levels of detrimental interactions, respectively [32-34].

\section{Statistical methods}

Data were analysed using IBM SPSS Version 24.0 for Windows. Descriptive statistics were used to describe demographic and clinical patient characteristics. Categorical variables are presented as $\mathrm{N}$ and percentage of total study population. Mean and standard deviation were used for describing continuous variables including illness perception, social support, and physical and mental quality of life. Exploratory linear regression models were used to assess the relationships between outcome variables (illness beliefs, social support) and potential covariates (demographic and clinical factors). Variables that retained independent associations with outcome at univariate level ( $p$-value $<0.2)$ were considered for multivariate analysis. Demographic and clinical characteristics were used as categorical variables. The different types of RA medication were included as dichotomous variables (yes/no) and illness perception, HRQoL and social support were included as continuous variables as listed in Tables 2 and 3 . All $p$-values are two-sided. Standardized $\beta$ s were used to compare the strength of independent variables.

\section{Results}

\section{Sample characteristics}

A total of 120 patients were included and completed the questionnaires. The demographic and clinical sample characteristics are presented in Table 2 . The majority of the included patients were female. The mean age was $54.2(\mathrm{SD}=12.9)$ and most of the patients had at least secondary school education. Most patients were either currently employed or permanently retired, had a monthly net income of between 1001 and $2000 €(1121-2240 \$)$ and were either married or living in a stable relationship. Disease duration was quite evenly distributed among patients, with only eight participants having a disease duration of less than 1 year (inclusion criteria: a stable
Table 2 Patient and clinical characteristics

\begin{tabular}{|c|c|}
\hline Variable & Total population $N=120(\%)$ \\
\hline \multicolumn{2}{|l|}{ Sex } \\
\hline Female & $99(82.5)$ \\
\hline Male & $21(17.5)$ \\
\hline \multicolumn{2}{|l|}{ Age } \\
\hline$<45$ years & $29(24.2)$ \\
\hline $45-65$ years & $65(54.2)$ \\
\hline$>65$ years & $26(21.7)$ \\
\hline \multicolumn{2}{|l|}{ Marital status } \\
\hline Single & $16(13.3)$ \\
\hline Married & $69(57.5)$ \\
\hline Divorced/living separated & $24(20.0)$ \\
\hline Widowed & $11(9.2)$ \\
\hline \multicolumn{2}{|l|}{ Educational level } \\
\hline Compulsory/lower secondary & $31(25.8)$ \\
\hline Secondary school/apprenticeship & $68(56.7)$ \\
\hline Higher education & $9(7.5)$ \\
\hline Other & $12(10.0)$ \\
\hline \multicolumn{2}{|l|}{ Monthly net income } \\
\hline$<1.000 €(1120 \$)$ & $23(19.2)$ \\
\hline $1.001-2000 €(1121-2240 \$)$ & $68(56.7)$ \\
\hline $2001-3000 €(224-3360 \$)$ & $20(16.7)$ \\
\hline$>3000 €(>3361 \$)$ & $9(7.5)$ \\
\hline \multicolumn{2}{|l|}{ Disease duration } \\
\hline$>10$ years & $35(42.5)$ \\
\hline $5-10$ years & $40(33.3)$ \\
\hline $1-4$ years & $34(30.8)$ \\
\hline$<1$ year & $8(6.7)$ \\
\hline \multicolumn{2}{|l|}{ RA treatment } \\
\hline NSAID & $51(42.5)$ \\
\hline sDMRAD & $106(88.3)$ \\
\hline bDMRAD & $38(31.7)$ \\
\hline Steroid & $29(24.2)$ \\
\hline Other & $11(9.2)$ \\
\hline \multicolumn{2}{|l|}{ Additional medication } \\
\hline No other medication & $34(28.3)$ \\
\hline 1-2 other medications & $45(37.5)$ \\
\hline 3-4 other medications & $19(37.5)$ \\
\hline$>4$ other medications & $22(18.3)$ \\
\hline \multirow[t]{2}{*}{ Presence of co-morbidity } & $62(51.7)$ \\
\hline & Mean (SD) \\
\hline Patient self-assessed (VAS) & $37.8(30.3)$ \\
\hline Disease activity & $34.7(29.4)$ \\
\hline Pain & $40.8(29.0)$ \\
\hline Functional disability & $38.3(31.0)$ \\
\hline
\end{tabular}

NSAID non-steroidal anti-inflammatory drug, sDMRAD synthetic diseasemodifying antirheumatic drug, $b D M A R D$ biologic disease-modying antirheumatic drug, VAS Visual analogue scale 0-100 
Table 3 Univariate analysis of associations between patient and clinical characteristics, illness perception, social support and HRQoL

\begin{tabular}{|c|c|c|c|c|}
\hline & Physical quality of life & $P$-value & Mental quality of life & $P$-value \\
\hline \multicolumn{5}{|l|}{ Patient characteristics } \\
\hline Sex & -0.06 & 0.500 & 0.01 & 0.940 \\
\hline Age & -0.13 & 0.152 & 0.12 & 0.177 \\
\hline Marital status & -0.15 & 0.100 & 0.09 & 0.323 \\
\hline Educational level & 0.14 & 0.122 & 0.07 & 0.429 \\
\hline Monthly net income & 0.11 & 0.256 & 0.14 & 0.121 \\
\hline \multicolumn{5}{|l|}{ Clinical characteristics } \\
\hline Disease duration & -0.06 & 0.550 & 0.16 & 0.078 \\
\hline \multicolumn{5}{|l|}{ Treatment } \\
\hline NDAID & 0.46 & $<0.001$ & 0.22 & 0.017 \\
\hline sDMARD & 0.05 & 0.624 & 0.06 & 0.517 \\
\hline bDMARD & -0.08 & 0.405 & 0.01 & 0.942 \\
\hline Steroid & 0.29 & 0.001 & 0.31 & $<0.001$ \\
\hline $\begin{array}{l}\text { Additional } \\
\text { medication }\end{array}$ & -0.34 & $<0.001$ & -0.28 & 0.002 \\
\hline Co-morbidity & -0.31 & $<0.001$ & -0.34 & $<0.001$ \\
\hline Disease activity & -0.56 & $<0.001$ & -0.54 & $<0.001$ \\
\hline Pain & -0.56 & $<0.001$ & -0.56 & $<0.001$ \\
\hline Functional disability & -0.56 & $<0.001$ & -0.61 & $<0.001$ \\
\hline Fatigue & -0.48 & $<0.001$ & -0.64 & $<0.001$ \\
\hline \multicolumn{5}{|l|}{ Illness perception } \\
\hline Identity & -0.39 & $<0.001$ & -0.39 & $<0.001$ \\
\hline Timeline (acute/chronic) & -0.11 & 0.228 & 0.03 & 0.719 \\
\hline Consequences & -0.61 & $<0.001$ & -0.56 & $<0.001$ \\
\hline Treatment control & 0.22 & 0.014 & 0.20 & 0.029 \\
\hline Personal control & 0.29 & 0.001 & 0.31 & 0.001 \\
\hline Illness coherence & 0.23 & 0.012 & 0.42 & $<0.001$ \\
\hline Timeline (cyclical) & -0.58 & $<0.001$ & -0.38 & $<0.001$ \\
\hline Emotional representation & -0.39 & $<0.001$ & -0.60 & $<0.001$ \\
\hline \multicolumn{5}{|l|}{ Social support } \\
\hline Positive support & 0.06 & 0.553 & 0.16 & 0.085 \\
\hline Detrimental interaction & -0.31 & 0.001 & -0.41 & $<0.001$ \\
\hline
\end{tabular}

Values shown are beta regression coefficients based on univariate regression analyses with dependent variable physical/mental HRQoL

disease and therapy). Most patients were on a therapy with synthetic disease-modifying antirheumatic drugs (sDMARDs) and one-third were receiving biological disease-modifying antirheumatic drugs (bDMARDs). More than half of the patients suffered from at least one co-morbidity and the majority of patients took at least one additional routine medication (other than RA medication).

\section{Physical health-related quality of life}

Univariate analysis (Table 3) revealed that the variables age, marital status, educational level, monthly net income, number of additional medications, presence of co-morbidity, pain, disease activity, functional disability, fatigue, detrimental social interaction and all dimensions of illness perception except timeline (acute/chronic) were significantly associated with physical HRQoL at the $p<0.2$ level and were therefore included in the multivariate analysis (Table 4). We did not include NSAID and steroid treatment due to multicollinearity with pain and disease activity. As shown in the crude regression model, which is not adjusted for possible confounders (Table 4, Model 1), consequences and timeline cyclical were associated with physical HRQL. This association remained stable when adjusted for demographic and clinical confounders and social support. These results indicate that RA patients 
Table 4 Regression models between illness perception items, patient characteristics, social support and dependent variable physical health-related quality of life (SF-36)

\begin{tabular}{|c|c|c|c|c|c|c|c|c|}
\hline & \multicolumn{2}{|c|}{ Model 1 (Block 1) } & \multicolumn{2}{|c|}{ Model 2 (Block 1-2) } & \multicolumn{2}{|c|}{ Model 3 (Block 1-3) } & \multicolumn{2}{|c|}{ Model 4 (Block 1-4) } \\
\hline & $\mathrm{R}^{2}$ & $\beta$ & $\overline{R^{2}}$ & $\beta$ & $\overline{R^{2}}$ & $\beta$ & $\mathrm{R}^{2}$ & $\beta$ \\
\hline \multicolumn{9}{|l|}{ Block 1} \\
\hline Illness perception & 0.511 & & 0.536 & & 0.565 & & .0 .565 & \\
\hline Identity & & -0.07 & & -0.08 & & -0.05 & & -0.05 \\
\hline Consequences & & $-0.37^{* *}$ & & $-0.39^{* *}$ & & $-0.34^{* *}$ & & $-0.34^{* *}$ \\
\hline Treatment control & & 0.04 & & 0.06 & & 0.04 & & 0.04 \\
\hline Personal control & & 0.14 & & 0.08 & & 0.03 & & 0.03 \\
\hline Illness coherence & & 0.01 & & -0.04 & & -0.04 & & -0.05 \\
\hline Timeline (cyclical) & & $-0.39^{* *}$ & & $-0.36^{* *}$ & & $-0.30^{* *}$ & & $-0.30^{* *}$ \\
\hline Emotional representation & & -0.05 & & -0.02 & & -0.01 & & -0.00 \\
\hline \multicolumn{9}{|l|}{ Block 2} \\
\hline \multicolumn{9}{|l|}{ Demographic characteristics } \\
\hline Age & & & & -0.16 & & -0.16 & & -0.16 \\
\hline Marital status & & & & -0.06 & & -0.08 & & -0.08 \\
\hline Educational level & & & & -0.04 & & -0.07 & & -0.07 \\
\hline \multicolumn{9}{|l|}{ Block 3} \\
\hline \multicolumn{9}{|l|}{ Clinical characteristics } \\
\hline Additional medication & & & & & & 0.03 & & 0.03 \\
\hline Co-morbidity & & & & & & -0.08 & & -0.08 \\
\hline Disease activity & & & & & & -0.03 & & -0.03 \\
\hline Pain & & & & & & 0.01 & & 0.01 \\
\hline Functional disability & & & & & & -0.18 & & -0.18 \\
\hline Fatigue & & & & & & -0.02 & & -0.02 \\
\hline \multicolumn{9}{|l|}{ Block 4} \\
\hline \multicolumn{9}{|l|}{ Social support } \\
\hline Detrimental interaction & & & & & & & & 0.08 \\
\hline$R^{2}$ change & & & 0.53 & & & 0.56 & & 0.63 \\
\hline
\end{tabular}

${ }^{*} p \leq 0.05 ;{ }^{* *} p \leq 0.01 ; \mathrm{R}^{2}$ is adjusted $\mathrm{R}^{2} ; \beta$ is standardized coefficient $\beta$

All variables with a $p$-value $<0.2$ in univariate analysis were included in the regression model

with stronger belief in the influence of RA on their daily life and stronger belief in the chronicity of the disease have lower physical HRQoL. In the multivariate analysis, none of the demographic characteristics, clinical parameters and social support were significantly associated with physical HRQoL.

\section{Mental health-related quality of life}

Univariate analysis (Table 3) revealed that the variables age and monthly net income, number of additional medications, presence of co-morbidity, pain, disease activity, functional disability, fatigue, positive as well as detrimental social interactions and all dimensions of illness perception except timeline (acute/chronic) were significantly associated with mental HRQoL at the $p<0.2$ significance level and were therefore included in the multivariate analysis (Table 5). In the regression model, which is not adjusted for possible confounders (Table 5, Model 1), consequences, illness coherence and emotional representation were associated with mental HRQL. When adjusted for clinical characteristics (Model 3), only illness coherence and emotional representation were associated with mental HRQoL, was along with fatigue. After additional adjustment for social support (Model 4), only emotional representation and fatigue remained significantly associated.

\section{Discussion}

RA has a substantial effect on HRQoL [35], and routine assessment of the disease's impact on a patient's life, including assessment of fatigue and HRQoL, has been recommended in recent guidelines [36]. In the present study, we assessed physical and mental HRQoL in an outpatient population of RA patients with stable disease course and examined illness perception and symptoms 
Table 5 Regression models between illness perception items, patient characteristics, social support and dependent variable mental health-related quality of life (SF-36)

\begin{tabular}{|c|c|c|c|c|c|c|c|c|}
\hline & \multicolumn{2}{|c|}{ Model 1 (Block 1) } & \multicolumn{2}{|c|}{ Model 2 (Block 1-2) } & \multicolumn{2}{|c|}{ Model 3 (Block 1-3) } & \multicolumn{2}{|c|}{ Model 4 (Block 1-4) } \\
\hline & $\mathrm{R}^{2}$ & $\beta$ & $\mathrm{R}^{2}$ & $\beta$ & $R^{2}$ & $\beta$ & $\mathrm{R}^{2}$ & $\beta$ \\
\hline \multicolumn{9}{|l|}{ Block 1} \\
\hline Illness perception & 0.452 & & 0.447 & & 0.554 & & 0.582 & \\
\hline Identity & & -0.12 & & -0.12 & & -0.02 & & -0.01 \\
\hline Consequences & & $-0.22^{*}$ & & $-0.21^{*}$ & & -0.07 & & -0.03 \\
\hline Treatment control & & -0.02 & & -0.03 & & -0.03 & & -0.01 \\
\hline Personal control & & 0.07 & & 0.09 & & 0.03 & & 0.01 \\
\hline Illness coherence & & $0.19^{*}$ & & $0.19^{*}$ & & $0.18^{*}$ & & 0.12 \\
\hline Timeline (cyclical) & & -0.06 & & -0.07 & & 0.04 & & 0.03 \\
\hline Emotional representation & & $-0.34^{* *}$ & & $-0.31^{* *}$ & & $-0.26^{*}$ & & $-0.27^{*}$ \\
\hline \multicolumn{9}{|l|}{ Block 2} \\
\hline \multicolumn{9}{|l|}{ Demographic characteristics } \\
\hline Age & & & & 0.08 & & 0.10 & & 0.08 \\
\hline Monthly net income & & & & 0.02 & & 0.03 & & 0.02 \\
\hline \multicolumn{9}{|l|}{ Block 3} \\
\hline \multicolumn{9}{|l|}{ Clinical characteristics } \\
\hline Additional medication & & & & & & -0.02 & & -0.02 \\
\hline Co-morbidity & & & & & & -0.09 & & -0.07 \\
\hline Disease activity & & & & & & 0.08 & & 0.13 \\
\hline Pain & & & & & & -0.12 & & -0.15 \\
\hline Functional disability & & & & & & -0.10 & & -0.11 \\
\hline Fatigue & & & & & & $-0.33^{* *}$ & & $-0.36^{* *}$ \\
\hline \multicolumn{9}{|l|}{ Block 4} \\
\hline \multicolumn{9}{|l|}{ Social support } \\
\hline Positive support & & & & & & & & 0.19 \\
\hline Detrimental interaction & & & & & & & & -0.10 \\
\hline$R^{2}$ change & & & & 0.43 & & 0.55 & & 0.58 \\
\hline
\end{tabular}

${ }^{*} p \leq 0.05 ; * * 0.01 ; \mathrm{R}^{2}$ is adjusted $\mathrm{R}^{2} ; \beta$ is standardized coefficient $\beta$

All variables with a $p$-value $<0.2$ in univariate analysis were included in the regression model

attributable to RA and their contribution to physical and mental HRQoL (SF-36).

The main finding of this study was, that in multivariate analysis, only two aspects of illness perception (consequences and cyclical timeline) explained 63\% variance in physical HRQoL and only one aspect of illness perception (emotional representation) and fatigue explained 58\% variance in mental HRQoL.

Our study supports the CSM, which states that people's beliefs about their illness are associated with their HRQoL. Although there are studies showing that the relation between illness perception and illness outcomes, including overall well-being, are mediated by coping with illness [37], there is evidence, that in chronic disease, illness perception has a stronger influence on HRQoL than coping strategies $[38,39]$.
In our study perceived little impact on daily life (consequences) and a weaker belief in the recurrence of RA (timeline cyclical) was associated with a higher score in physical HRQoL. In a qualitative study on fears and beliefs in rheumatoid arthritis the unpredictability of the disease course was a common source of anxiety, however, these fears were lower in remission but when exacerbations occurred, or a treatment stopped working initial fears were reactivated. The variability in the course was in itself a major source of uncertainty and worries. Also, no longer being able to manage activities of daily living was a common fear on the impact of the disease. This covered all aspects of daily living from getting up to driving or climbing stairs [40].

Our finding that patients with a weaker emotional response to their disease is associated with a better mental 
HRQoL is in line with previous studies on RA [41] and other chronic diseases [42].

Fatigue had a significant impact on mental HRQoL in our fully adjusted model. A literature review [2] reported that unacceptable levels of fatigue persisted in a substantial proportion of patients with RA, despite the introduction of intensive treatments and the fact that a majority of patients with RA believed that reducing fatigue should be a key treatment aim, although fatigue-related end points were rarely reported in clinical trials.

In a study comparing the relative predictive value of disease status and illness perception, clinical variables explained some but illness perception explained the biggest part of the variance in disease-specific functioning [43]. Also, in our population in univariate regression, demographics and the clinical parameters co-morbidity, number of co-medications, disease activity, functional disability, pain and fatigue were significantly associated with physical and mental HRQoL, but when adapting these variables in the multivariate regression with illness beliefs, only fatigue remained a significant contributor to mental HRQoL.

The mean physical SF-36 score reported in this study was 38.38 and the mean mental SF-36 summary score was 46.94 .

These findings are in line with a previous study and a review [6, 35], that reported similar score levels for the RA population compared to significantly higher levels in the general population.

Notably, a higher age was associated with a reduced physical HRQoL but higher mental HRQoL, supporting two previous reviews that reported positive associations between age and mental HRQoL as well as negative associations between the prevalence of depression and age in RA [35, 44].

Here the question arises, if a chronic disease like RA has a stronger impact on younger patients, as it is more difficult for them to accept the limitations caused by the disease (e.g. loss of workability).

Illness coherence was associated with mental HRQoL in univariate and multivariate regression before adjustment to social support, suggesting that people with better knowledge of their disease have a better mental HRQoL. Low health literacy was shown to be associated with functional impairments and disease severity [45] but has until now been reported in association with HRQoL in RA. The better patients knew their disease, the better they experienced mental HRQoL, presumably due to the security of knowing the disease and what to expect in the course of disease and treatment. To the best of our knowledge, the positive impact of better disease understanding on QoL has not been studied in RA patients before and might be interesting for future studies.
When interpreting this study's results, several points should be taken into consideration.

First, a theoretical concern is the conceptual overlap between specific illness perceptions, disease parameters and HRQoL: E.g. 'identity' overlaps with subjectively perceived disease activity/pain (VAS scales). Here the use a standard tool to assess disease activity would cause less overlap. 'Consequences' overlaps with physical aspects and emotional representation with emotional aspects of quality of life scales. These overlaps have been already discussed e.g. in a study on patients with inflammatory bowel disease [46]. Also, according to cognitive behavioural theory, we hypothesized that a trigger (RA) leads to a cognitive process (illness perception) which influences emotional and behavioural factors (HRQoL). It is however possible, that in turn poor HRQoL due to other factors/ circumstances leads to more negative illness perceptions.

Second, this study is limited due to its cross-sectional and monocentric character, which does not allow final conclusions to be drawn about the direction and causality of the impact of illness perception on HRQoL. The present study assesses how current illness perception is associated with the current HRQoL in RA patients. The fact that (a singular assessment of) illness perceptions only represent how the patient currently thinks, feels and understands about his/her medical condition and do not portray illness perception as an independent psychological factor, trait or process has to be taken into account [47]. Illness perception is dynamic, can change over time and is amenable to intervention [48], thus a causal relationship can only be verified through a longitudinal study potentially including psychological interventions. Illness perception-focused intervention and its effect on quality of life has been studied, for example, for patients with myocardial infarction and their spouses $[49,50]$ but not for RA, and is thus an interesting objective for an intervention study on RA. Third, the study population primarily consisted of female participants, reflecting the characteristic population distribution of RA patients, but also features the advantage of a balanced distribution of age and disease duration indicating a representative group of RA patients. Also, the study population was limited to participants with a stable disease course for at least 3 months, which excluded e.g. patients with acute disease flares. Patients with currently unstable disease might report other dimensions of illness perception and associations to HR QoL might differ broadly. Thus, these findings are possibly not generalizable to the entire RA population. Fourth, disease activity was assessed using a self-reported parameter and not by means of a recognized objective assessment tool such as the clinical disease activity index and may therefore not be comparable to other study results.

Despite these limitations, this study provides additional information to determinants of HRQoL in RA patients. 
To our knowledge multiple studies exist on the relation on illness perception on e.g. depression, subjective disease assessment or disability but only few to measure the relation of illness perception of HRoL in RA.

In RA, beliefs about the disease appear to evolve over the course of the disease [40] and illness perceptions are well defined as target to treatment in cognitive behavioural therapy[51]. A substantial finding of this study was, that in patients with stable RA illness perceptions were associated with HRQoL rather than clinical parameters. Given the low HRQoL in RA patients, beside pharmaco-, and physiotherapy, a psychological support could be added for a complete treatment approach. To our knowledge no interventional study was published on illness perception focused therapy on RA patients yet [52]. The results of this study suggest, that targeting illness perception could be tested in psychological interventions to improve HROoL, which has been shown e.g. for musculoskeletal pain [53].

\section{Conclusion}

This study showed that current illness perception accounts for a large part of the variance in physical and mental health-related quality of life after adjusting for demographics, clinical variables and social support. Although a longitudinal study with illness perception intervention is needed to assess the stability of beliefs and associated changes in HRQoL, the present study showed that the characterization of a patient's illness perception is associated with his/her HRQoL. The question if HRQoL can be positively influenced by alleviating the perceived threat of their illness and strengthening positive illness beliefs would be an interesting matter for future research.

\section{Abbreviations}

CSM: Common-sense model; HRQoL: Health-related quality of life; IPQ: Illness perception questionnaire; IPQ-R: Revised, RA-specific version of IPQ-R; MCS: Mental component summary; PCS: Physical component summary; RA: Rheumatoid arthritis; SF-36: Medical outcome study 36-item short-form health survey; SSUK-8: Eight-item illness-specific social support scale

\section{Acknowledgements}

The study was supported by the Karl Landsteiner society - institute for rheumatic and autoimmune disease (no financial but personal and material support).

\section{Funding}

This study received no funding.

\section{Availability of data and materials}

The datasets used and/or analysed during the current study are available from the corresponding author on reasonable request.

\section{Authors' contributions}

TED and LE created the concept of the study, KHF contributed to data collection, CB was responsible for analysis and interpretation of the data and for drafting of the manuscript. All authors critically revised the article and gave final approval of the version to be published.

\section{Ethics approval and consent to participate}

The study was conducted in accordance with the Helsinki Declaration. Ethical review committee approval was obtained from the city government of Vienna (ERB no.: EK-13-190-VK). Participants received detailed information about the study and written informed consent was obtained from each patient before enrolment.

\section{Consent for publication}

This manuscript does not contain individual person's data in any form.

\section{Competing interests}

The study was supported by the Karl Landsteiner society - institute for rheumatic and autoimmune disease. The authors declare that they have no competing interests.

\section{Publisher's Note}

Springer Nature remains neutral with regard to jurisdictional claims in published maps and institutional affiliations.

\section{Author details \\ 'Sozialmedizinisches Zentrum-Süd, Department of Rheumatology and Osteology, Kaiser Franz Josef Hospital, Vienna Kundratstrasse 3, 1100 Vienna, Austria. ${ }^{2}$ Karl Landsteiner Institute for Autoimmune Diseases and Rheumatology, Vienna, Austria. ${ }^{3}$ Department for Social and Preventive Medicine, Centre for Public Health, Medical University of Vienna, Vienna, Austria.}

Received: 6 February 2018 Accepted: 10 December 2018

Published online: 19 December 2018

\section{References}

1. Alamanos Y, Voulgari PV, Drosos AA. Incidence and prevalence of rheumatoid arthritis, based on the 1987 American College of Rheumatology criteria: a systematic review. Semin Arthritis Rheum. 2006;36:182-8.

2. Taylor PC, Moore A, Vasilescu R, Alvir J, Tarallo M. A structured literature review of the burden of illness and unmet needs in patients with rheumatoid arthritis: a current perspective. Rheumatol Int. 2016;36:685-95.

3. Affleck G, Tennen H, Keefe FJ, Lefebvre JC, Kashikar-Zuck S, Wright K, Starr K, Caldwell DS. Everyday life with osteoarthritis or rheumatoid arthritis: independent effects of disease and gender on daily pain, mood, and coping. Pain. 1999;83:601-9.

4. Papadopoulos IA, Katsimbri P, Alamanos Y, Voulgari PV, Drosos AA. Early rheumatoid arthritis patients: relationship of age. Rheumatol Int. 2003;23:70-4.

5. Nicassio PM, Kay MA, Custodio MK, Irwin MR, Olmstead R, Weisman MH. An evaluation of a biopsychosocial framework for health-related quality of life and disability in rheumatoid arthritis. J Psychosom Res. 2011;71:79-85.

6. Uhlig T, Loge JH, Kristiansen IS, Kvien TK. Quantification of reduced health-related quality of life in patients with rheumatoid arthritis compared to the general population. J Rheumatol. 2007;34:1241-7.

7. Kvien TK, Uhlig T. Quality of life in rheumatoid arthritis. Scand J Rheumatol. 2005;34:333-41.

8. Russell AS. Quality-of-life assessment in rheumatoid arthritis. Pharmacoeconomics. 2008:26:831-46.

9. Helgeson VS. Social support and quality of life. Qual Life Res. 2003;12(Suppl 1): 25-31.

10. Minnock P, Fitzgerald O, Bresnihan B. Quality of life, social support, and knowledge of disease in women with rheumatoid arthritis. Arthritis Rheum. 2003:49:221-7.

11. Strating MM, Suurmeijer TP, van Schuur WH. Disability, social support, and distress in rheumatoid arthritis: results from a thirteen-year prospective study. Arthritis Rheum. 2006;55:736-44.

12. Keefe FJ, Smith SJ, Buffington AL, Gibson J, Studts JL, Caldwell DS. Recent advances and future directions in the biopsychosocial assessment and treatment of arthritis. J Consult Clin Psychol. 2002;70:640-55.

13. Leventhal $Y B$ H, Brownlee $S$, Diefenbach M, Leventhal EA, Patrick-Miller $L$, Robitaille C. Illness representation: theoretical foundations. Perceptions of health and illness. Amsterdam: Harwood; 1997. p. 19-46.

14. de Ridder D, Geenen R, Kuijer R, van Middendorp H. Psychological adjustment to chronic disease. Lancet. 2008;372:246-55.

15. Leventhal HLBI, Leventhal EA. Common-sense model of self-regulation of health and illness. In: Cameron LDLH, editor. The self-regulation of health and illness behaviour. London: Routledge; 2003. p. 42-65. 
16. Lochting I, Fjerstad E, Garratt AM. IIIness perceptions in patients receiving rheumatology rehabilitation: association with health and outcomes at 12 months. BMC Musculoskelet Disord. 2013;14:28.

17. Petrie KJ, Weinman J. Why illness perceptions matter. Clin Med (Lond). 2006: 6:536-9.

18. Leventhal HNDR, Steele DJ. Illness representation and coping with health threats. In: Ba S, editor. A Hand-book of Psychology and Health, vol. 4. Hillsdale: NJ:Erlbaum. p. 1984.

19. Groarke A, Curtis R, Coughlan R, Gsel A. The role of perceived and actual disease status in adjustment to rheumatoid arthritis. Rheumatology (Oxford). 2004;43:1142-9.

20. Dempster M, Howell D, McCorry NK. Illness perceptions and coping in physical health conditions: a meta-analysis. J Psychosom Res. 2015;79:506-13.

21. Maas $M$, Taal $E$, van der Linden $S$, Boonen A. A review of instruments to assess illness representations in patients with rheumatic diseases. Ann Rheum Dis. 2009;68:305-9.

22. Cordingley L, Prajapati R, Plant D, Maskell D, Morgan C, Ali FR, Morgan AW, Wilson AG, Isaacs JD, Barton A. Impact of psychological factors on subjective disease activity assessments in patients with severe rheumatoid arthritis. Arthritis Care Res (Hoboken). 2014;66:861-8.

23. Carlisle AC, John AM, Fife-Schaw C, Lloyd M. The self-regulatory model in women with rheumatoid arthritis: relationships between illness representations, coping strategies, and illness outcome. Br J Health Psychol. 2005;10:571-87.

24. Stanton AL, Revenson TA, Tennen H. Health psychology: psychological adjustment to chronic disease. Annu Rev Psychol. 2007:58:565-92.

25. Ware JE Jr, Sherbourne CD. The MOS 36-item short-form health survey (SF-36). I Conceptual framework and item selection. Med Care. 1992;30:473-83.

26. Ware JE, Snow KK, Kosinski M, et al. SF-36 Health Survey Manual and Interpretation Guide. Boston, MA: New England Medical Center, The Health Institute, 1993.

27. Linde L, Sorensen J, Ostergaard M, Horslev-Petersen K, Hetland ML. Health-related quality of life: validity, reliability, and responsiveness of SF-36, 15D, EQ-5D [corrected] RAQoL, and HAQ in patients with rheumatoid arthritis. J Rheumatol. 2008;35:1528-37.

28. Bullinger M. German translation and psychometric testing of the SF-36 health survey: preliminary results from the IQOLA project. International Quality of Life Assessment. Soc Sci Med. 1995;41:1359-66.

29. Moss-Morris RWJ, Petrie KJ, Horne R, Cameron LD, Buick D. The revised illness perception questionnaire (IPQ-R). Psychol Health. 2002;17:1-16.

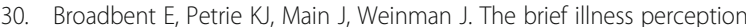
questionnaire. J Psychosom Res. 2006;60:631-7.

31. Glattacker M. German version of the illness perception questionnaire-revised (IPQ-R): psychometric evaluation in patients with chronic somatic illness. Zeitschrift für Gesundheitspsychologie. 2009:17:158-69.

32. Revenson TA, Schiaffino KM. Development of a contextual social support measure for use with arthritis populations. Seattle: Paper presented at 1990 Convention of the Arthritis Health Professionals' Association; 1990.

33. Mehnert AUA. Psychometrische Evaluation and Validierung einer 8-ItemKurzversion der Skalen zur Sozialen Unterstützung bei Krankheit (SSUK) bei Krebspatienten. Klin Diagnostik u Evaluation. 2010;3:359-81.

34. Ramm GHM. The German adaptation of the illness-specific social support scale and the test statistical evaluation on the basis of patients undergoing bone marrow transplantation. Z Med Psychol. 2003;12:29-38.

35. Matcham F, Scott IC, Rayner L, Hotopf M, Kingsley GH, Norton S, Scott DL, Steer $\mathbf{S}$. The impact of rheumatoid arthritis on quality-of-life assessed using the SF-36: a systematic review and meta-analysis. Semin Arthritis Rheum. 2014:44:123-30

36. Loignon C, Haggerty JL, Fortin M, Bedos CP, Barbeau D, Allen D. What makes primary care effective for people in poverty living with multiple chronic conditions?: study protocol. BMC Health Serv Res. 2010;10:320.

37. Hagger MOS. A meta-analytic review of the common-sense model of illness representations. Psychol Health. 2003;18:141-84.

38. Heijmans MJ. Coping and adaptive outcome in chronic fatigue syndrome: importance of illness cognitions. J Psychosom Res. 1998;45:39-51.

39. Weldam SW, Lammers JW, Decates RL, Schuurmans MJ. Daily activities and health-related quality of life in patients with chronic obstructive pulmonary disease: psychological determinants: a cross-sectional study. Health Qual Life Outcomes. 2013;11:190.

40. Berenbaum F, Chauvin P, Hudry C, Mathoret-Philibert F, Poussiere M, De Chalus T, Dreuillet C, Russo-Marie F, Joubert JM, Saraux A. Fears and beliefs in rheumatoid arthritis and spondyloarthritis: a qualitative study. PLoS One. 2014;9:e114350.

41. Graves $H$, Scott DL, Lempp H, Weinman J. Illness beliefs predict disability in rheumatoid arthritis. J Psychosom Res. 2009;67:417-23.

42. Weldam SW, Lammers JW, Heijmans MJ, Schuurmans MJ. Perceived quality of life in chronic obstructive pulmonary disease patients: a cross-sectional study in primary care on the role of illness perceptions. BMC Fam Pract. 2014;15:140.

43. Scharloo M, Kaptein AA, Weinman J, Hazes JM, Willems LN, Bergman W, Rooijmans HG. Illness perceptions, coping and functioning in patients with rheumatoid arthritis, chronic obstructive pulmonary disease and psoriasis. J Psychosom Res. 1998:44:573-85.

44. Matcham F, Rayner L, Steer S, Hotopf M. The prevalence of depression in rheumatoid arthritis: a systematic review and meta-analysis: reply. Rheumatology (Oxford). 2014;53:578-9.

45. Hirsh JM, Boyle DJ, Collier DH, Oxenfeld AJ, Nash A, Quinzanos I, Caplan L. Limited health literacy is a common finding in a public health hospital's rheumatology clinic and is predictive of disease severity. J Clin Rheumatol. 2011;17:236-41.

46. De Gucht V. Illness perceptions mediate the relationship between bowel symptom severity and health-related quality of life in IBS patients. Qual Life Res. 2015;24:1845-56.

47. Falzer PR. IIIness perception theory in arthritis research and practice: comment on the article by Cordingley et al. Arthritis Care Res. 2015;67:452.

48. Petrie KJ, Cameron LD, Ellis CJ, Buick D, Weinman J. Changing illness perceptions after myocardial infarction: an early intervention randomized controlled trial. Psychosom Med. 2002:64:580-6.

49. Sararoudi RB, Motmaen M, Maracy MR, Pishghadam E, Kheirabadi GR. Efficacy of illness perception focused intervention on quality of life, anxiety, and depression in patients with myocardial infarction. J Res Med Sci. 2016;21:125.

50. Broadbent E, Ellis CJ, Thomas J, Gamble G, Petrie KJ. Can an illness perception intervention reduce illness anxiety in spouses of myocardial infarction patients? A randomized controlled trial. J Psychosom Res. 2009;67:11-5.

51. Christensen SS, Frostholm L, Ornbol E, Schroder A. Changes in illness perceptions mediated the effect of cognitive behavioural therapy in severe functional somatic syndromes. J Psychosom Res. 2015;78:363-70.

52. Foster NE, Bishop A, Thomas E, Main C, Horne R, Weinman J, Hay E. Illness perceptions of low back pain patients in primary care: what are they, do they change and are they associated with outcome? Pain. 2008;136:177-87.

53. Siemonsma PC, Stuive I, Roorda LD, Vollebregt JA, Walker MF, Lankhorst GJ, Lettinga AT. Cognitive treatment of illness perceptions in patients with chronic low back pain: a randomized controlled trial. Phys Ther. 2013;93:435-48.

Ready to submit your research? Choose BMC and benefit from:

- fast, convenient online submission

- thorough peer review by experienced researchers in your field

- rapid publication on acceptance

- support for research data, including large and complex data types

- gold Open Access which fosters wider collaboration and increased citations

- maximum visibility for your research: over $100 \mathrm{M}$ website views per year

At $\mathrm{BMC}$, research is always in progress.

Learn more biomedcentral.com/submissions 